\title{
Mindfulness Practices that Can be Implemented in the Regular Classroom
}

\author{
Dorothy Sisk* \\ Consultant Editor and Director of the Gifted Child Centre, University of Lamar, USA
}

Submission: August 11, 2017; Published: September 13, 2017

*Corresponding author:Dorothy Sisk, Consultant Editor and Director of the Gifted Child Centre, Lamar University, USA, Email: siskda@lamar.edu

\section{Introduction}

Gandhi's words remind us that as teachers working with children and youth, we are agents of change. Mindfulness can provide insight to enable teachers and administrators to envision and create a new model or approach to education. Mindfulness is not a new idea since William James [1] said, "The faculty of voluntarily bringing back a wandering attention, over and over again, is the very root of judgment, character and will." This is mindfulness, as James continued, "an education which should improve this faculty would be the education par excellence."

Mindfulness is being aware of what is happening within us and around us with a clear focus of our attention on moment-tomoment experience in the here and now [2]. Gifted students are sensitive and have great depth in their thinking and feeling, and these characteristics can be positively directed with mindfulness activities. As gifted students engage in mindfulness activities, they can strengthen their inner awareness and vision. However, their sensitivity and depth in thinking and feeling can result in painful experiences when gifted students feel out of sync with other students and their teachers [3].

Mindfulness has ancient roots; but, incredible applications employing mindfulness activities are being made daily in medicine, business and education. Two very different people Thich Nhat Hanh, a Vietnamese Buddhist monk and an American medical physician Jon Kabat-Zinn have worked with mindfulness over the last 40 years, with amazing contributions. More and more educators are viewing mindfulness activities as a viable strategy and practice to use with students to enhance mental, emotional, physical and spiritual wellness.

Thich Nhat Hanh [4] has written five books in the Mindfulness Essential Series including How to sit which provides clear and simple directions for exploring mindfulness. The second book How to relax [5] addresses the daily stress that makes us less productive and less happy. In this book Thich Nhat Hanh shares techniques for bringing your life back into balance. The third book How to walk [6] reminds us that we touch the Earth with awareness, and to stop sleepwalking to arrive fully in the present moment. The fourth book How to Love [7] brings clarity, compassion and humor to the essential question of how to love. The fifth book How to Eat [8] tells how the process of eating can be a joyful and sustainable activity, including preparing the food, and even cleaning up after the meal. In How to Walk [6] Thich Nhat Hanh emphasized love of the Earth, and he said we can express love of the Earth with each step. You can say:
a. With each step
b. I come home to the Earth
c. With each step
d. I return to my source [6].

Jon Kabat-Zinn began his work in mindfulness by establishing the Mindfulness-Based Stress Reduction (MBSR) clinic at the Massachusetts Medical Center in 1979. At that time, the word mindfulness was nowhere in the medical lexicon. Today, nearly 23,000 certified MBSR instructors teach mindfulness techniques, including meditation and the clinics are in nearly every state in the United States and in more than 30 countries.

Early on Kabat-Zinn worked with treatment resistant patients of other doctors, and after 8 weeks of mindfulness training, the treatment resistant patients showed remarkable transformation. The MBSR patients had symptom reduction in blood pressure, psoriasis, and fibromyalgia, and patients with chronic pain disorder reported a greater sense of wellbeing $[9,10]$. Randomized controlled trials and studies show impressive reduction in psychological morbidity, stress and enhanced emotional well-being in non-clinical samples [11] Kabat Zinn reported that participants in MBSR training tend to speak of the mindfulness experience as transformative [12]. 


\section{Sense of connectedness}

Mindfulness builds a sense of connectedness, and recognition of the similarities in people. In today's classroom with the growing diversity of the student population, it is essential that all students are encouraged to develop a respect and connection with others. One powerful mindfulness activity that positively impacts the need for connection is deep listening. Deep listening involves giving full attention to another person and maintaining a present-centered awareness. Gifted students with their many interests and deep passion for their individual projects may find deep listening a challenge. Many gifted students report they give minimal attention to their teachers until they "hear" something they don't already know or are of interest to them. This behavior can be problematic in gifted student-teacher interaction. All students can benefit from deep listening not only for academic achievement, but for greater social awareness and ability to get along with others. Several programs have been developed to help teachers integrate mindfulness into their regular classrooms.

\section{Care}

Patricia Jennings [13] a professor from the University of Virginia developed CARE a mindfulness program for students and teachers. The goal was to promote a wholesome way of learning and living. Students reflect on their patterns of behavior, thoughts and emotions in journals. As they engage in reflection, students can see the importance of taking responsibility for building positive interactions with their teachers and other students.

\section{Transformative life skills}

Jennifer Frank, a professor at Penn State University collaborated with Niroga Institute to develop the program called Transformative Life Skills (TLS). The program combines mindful yoga, breathing techniques and meditation. The three core practices are action, breathing and centering. Action includes mindful movement and yoga postures; the breathing component helps individuals manage stress; and the centering component brings awareness to the present moment. A pilot study of TLS found the program reduced stress and improved well-being in a sample of 49 high-risk high school students [14].

\section{Learning to breathe}

Learning to Breathe was developed by Patricia Broderick [15] and it is based on six themes following the acronym BREATHE. $\mathrm{B}$ is for body awareness, $\mathrm{R}$ is for reflection and understanding, and working with thoughts, $\mathrm{E}$ is for understanding and working with feelings, $A$ is for integrating awareness of thoughts, feelings, and bodily sensations, $\mathrm{T}$ is for tenderness, taking it as it is, and reducing harmful self-judgment, $\mathrm{H}$ is for habits for a healthy mind, integrating mindful awareness into daily life, and $\mathrm{E}$ is for empowerment. Metz et al. [16] in their research found high school students engaged in learning to Breathe reported lower stress levels, negative effect, psychosomatic complaints, and increased levels of efficacy and emotional regulation.

\section{Inner kids}

Susan Kaiser-Greenland designed Inner Kids with a focus on attention, balance and compassion. The program seeks to develop awareness of inner experiences, one's thoughts, emotions, and physical sensations; awareness of outer experiences of other people, places and things; and the importance of how these two inner and outer experiences blend together. Inner Kids was found to be particularly helpful in working with students [17]. In addition, Inner Kids helped address the emotional issues that students experience, including their use of intellectual power. Their speed of thought, high level questions and comments often cause rejection by classmates and gifted students may need help in understanding this rejection.

\section{Mind up}

MindUp focuses on four areas: 1) How Our Brains Work, 2) Sharpening Your Senses, 3) it's All About Attitude, and 4) Taking Action Mindfully. MindUp is integrated into most elementary schools in the southern mainland of British Columbia, Canada, and in the United States, the program was adopted by the city of Newark, New Jersey. MindUp was developed by the Hawn Foundation in British Columbia when actress Goldie Hawn lived in Vancouver. Kimberly Schonert-Reichl conducted several research studies of MindUp and reported that students in the program were more optimistic and self- confident and their teachers said they demonstrated more social competence [18].

\section{Kripalu schools}

Kripalu Yoga in Schools (KYSIS) works with adolescents to help them learn social and emotional regulation, stress management, self-appreciation and self-confidence and relationship skills. A pilot study of the KYSIS program integrated yoga and mindfulness activities into regular high school programming. Noggle et al. [19] reported that the KYSIS students showed improvement in mood disturbances of students and lessened their anxiety.

\section{Mindfulness activities with high school gifted students}

The Texas Governor's School (TGS) is a residential program for high achieving and high ability students from throughout the state of Texas. In 2017, the staff and director decided to plan and implement a mindfulness program for the 73 students attending the three week program using the evidence based research and suggested activities of five Mindfulness programs (Kripalu Yoga, MindUp, Breathe, Inner Kids and Transformative Life Skills. Specific activities were selected including Mindful Walking, Awareness Breathing, Belly Breathing, Mindful Movement, Mindful Eating, Visualization and Loving Kindness Meditations.

Awareness Breathing included the students watching and becoming aware of breathing in and out. They breathed in and counted 1-2-3, held the breath 1-2-3 and exhaled 1-2-3. Belly Breathing involved placing an object or pillow on the stomach of each student and watching and feeling it rise and fall with each breath. Mindful Walking involved the students in walking slowly 
around the track at the University while concentrating on their deep breathing and paying attention to their senses, noting what they were hearing, seeing, smelling or feeling as they walked. The following gatha was used:

\section{a. Breathing in, I am aware of my feet. \\ b. Breathing out, I smile at my feet.}

Mindful movement included several yoga positions including the Sun Salutation which they did with their counselor each morning before breakfast. Mindful Eating involved the students tasting a raisin and holding it in their mouth for several minutes before finally swallowing it. They also tasted a marshmallow with the same intense concentration. A snack meditation with tangerines was used with the students eating the tangerine slowly and mindfully as if it were the most important thing for them to do in their life.

Visualization included a number of visualizations provided by Dr. Sisk involving the classic Three Boxes developed and demonstrated by Maslow [20] and the wise seer on the mountain from the book the Growing Person [21]. Loving Kindness included a number of Loving Kindness mantras using several of Thich Nhat Hanh's gathas in his five books, and a favorite from Goldstein [22] was:
a. May I be happy
b. May I be peaceful
c. May I be free from suffering.

\section{Participants and Methodology}

The students ranged in ages 14-18 in grades 10-12. The mindfulness sessions were 30 minutes daily M-F. Each student was assigned to a counselor and the group of students ranged from 10-12 students in a "family." The counselors reinforced the strategies in evening sessions with their family of students. Observations indicated that most students were able to block out any noise or distractions during the mindfulness exercises. Dr. Sisk, the director trained the counselors in the use of the mindfulness strategies, and she conducted the meditation and visualization sessions. Each of the students wrote a daily reflective journal entry after the mindfulness activities. These entries were examined for themes. Themes that emerged were a feeling of calmness, sensory awareness, enjoyment, and a sense of peace.

The students were administered a Mindful Attention Awareness Scale that was developed by Ruth Baer at the University of Kentucky. In addition, the students were also administered a Leadership Skills and Behaviors Scale developed by Sisk [23] that measures self-concept and motivation.

Results

Pre-test scores in Mindfulness were 3.95 and post-test scores were 4.28. Pre-test scores in self-concept were15.33 and post- test scores were 16.92. Motivation [24] pre-test scores were 23.90 and post-test scores were 25.18. Paired t test results showed significant difference in the three test scores at the .01 level.

\section{Conclusion}

In our troubled times, mindfulness offers a strategy particularly suited for gifted students to reduce their anxiety and stress, but mindfulness can be implemented with all students of different abilities. It will be important as teachers approach the use of mindfulness [25] with their students, that they do so with an open-heart, present moment, nonjudgmental awareness. The benefits for both the teacher and the students will be life changing. One easy way to get involved in incorporating mindfulness in your life and in your classroom is to connect with others who are trying to do the same thing. Websites and resources in the references of this article will help get you started, and there are free audio recordings of guided mindfulness practices that you can download. Mindfulness activities and programs can truly transform your classroom.

\section{References}

1. James W (1950) The principles of psychology. NY: Dover, New York, USA.

2. Sisk D, Kane M (2017) Planting seeds of mindfulness. NY: Royal Fireworks Press, New York, USA.

3. Tolan S (2016) Out of Sync: Essays on giftedness. NY: Royal Fireworks Press, USA.

4. Hanh TN (2014) How to sit. CA: Parallax Press, Berkeley, USA.

5. Hanh TN (2015b) How to relax. CA: Parallax Press, Berkeley, USA.

6. Hanh TN (2015a) How to walk. CA: Parallax Press, Berkeley, USA.

7. Hanh TN (2015c) How to love. CA: Parallax Press, Berkeley, USA.

8. Hanh TN (2014) How to eat. CA: Parallax Press, Berkeley, USA.

9. Kabat Zinn J (1982) An out-patient program in behavioral medicine for chronic pain patients based on the practice of mindful meditation. Clinical Joint Pain 4(1): 159-173.

10. Kabat Zinn J (1998) Psycho-oncology Meditation. In: Holland JC (Ed.), NY: Oxford University Press, USA, pp. 767-779.

11. Williams K, Kolar M, Roger B, Pearson J (2001) Evaluation of a wellnessbased mindfulness stress reduction intervention: A controlled trial. American Journal of Health Promotion 15(6): 422-432.

12. Kabat Zinn J (2003) Mindfulness-based interventions in context: Past, present and future. Clinical Psychology: Science and Practice 10(2): 144-156.

13. Jennings $P$ (2015) Mindfulness for teachers. NY: WW Norton \& Co, New York, USA.

14. Jennifer L, Frank J, Bose B, Schrobenhauser-Clonan A (2014) Effectiveness of a school-based yoga program on adolescent mental health, stress, coping strategies, and attitudes toward violence. Findings from a high-risk sample. Journal of Applied School Psychology 30(1): 29-49.

15. Broderick P (2013) Learning to Breathe: A mindfulness curriculum for adolescents to cultivate emotion regulation, attention, and performance. CA: New Harbinger, Oakland, USA. 
16. Metz S, Frank J, Reibel D, Cantrell T, Sanders R, et al, (2013) The effectiveness of the Learning to Breathe program on adolescent emotion regulation. Research in Human Development 10: 252-272.

17. Flook L, Smalley SL, Kitil MJ, Galla B, Kaiser Greenland S, et al, (2010) Effects of mindful awareness practices on executive functions in elementary school children. Journal of Applied School Psychology 26(1): 70-95

18. Schonert Reichl K, Lawlor M (2010) The effects of a mindfulness-based education program on pre and early adolescents' well-being and social and emotional competence. Mindfulness 1(3): 137-15l.

19. Noggle J, Steiner J, Minami T, Khalsa S (2012) Benefits of Yoga for psychosocial well-being in a US high school curriculum:. Preliminary randomized controlled trial. Journal of Developmental Behavior 33(3): 193-201.

his work is licensed under Creative Commons Attribution 4.0 License DOI: 10.19080/JYP.2017.02.555599
20. Maslow A (1968) Toward a psychology of being. NJ: Van Nostrand, Princeton, USA.

21. Sisk D, Shallcross (1982) The Growing Person. NY: Bearly Limited Press, Buffalo, USA

22. Goldstein J (2007) A heart full of peace. MA: Wisdom Publications, Boston, USA.

23. Sisk D, Rosselli H (1987) Leadership Skills \& Behaviors Scale. In Leadership: A special type of giftedness. NY: Trillium Press, Unionville, Canada.

24. Tolan S (2016) Out of Sync: Essays on giftedness. NY: Royal Fireworks Press, Unionville, Canada.

25. Siegel D (2014) Brainstorm: The power and purpose of the teenage brain. NY: Tarcher New York, USA.

\section{Your next submission with Juniper Publishers} will reach you the below assets

- Quality Editorial service

- Swift Peer Review

- Reprints availability

- E-prints Service

- Manuscript Podcast for convenient understanding

- Global attainment for your research

- Manuscript accessibility in different formats ( Pdf, E-pub, Full Text, Audio)

- Unceasing customer service

Track the below URL for one-step submission https://juniperpublishers.com/online-submission.php 